\title{
LXXI. On the action of ammonia on the protochloride and peroxide of mercury
}

\author{
Robert Kane M.D. M.R.I.A.
}

To cite this article: Robert Kane M.D. M.R.I.A. (1837) LXXI. On the action of ammonia on the protochloride and peroxide of mercury, Philosophical Magazine Series 3, 11:70, 504-512, DOI: $10.1080 / 14786443708649341$

To link to this article: http://dx.doi.org/10.1080/14786443708649341

册 Published online: 01 Jun 2009.

Submit your article to this journal $\lceil\pi$

Џ Article views: 2

Q View related articles $\asymp$ 
into a full investigation of this theory mathematically: but now my age forbids; it remains therefore only for me earnestly to recommend these labours, which I am sure will yield abundant fruit, to the consideration of the real lovers of science.

Bristol, Sept. 29th. 1837.

Thomas Exley.

LXXI. On the Action of Ammonia on the Protochloride and Peroxide of Mercury. By Robert Kane, M.D., M.R.I.A., \&c. \&c.*

\section{Of the Action of Ammonia on the Protochloride of Mercury.}

$\$ 1 .-$ Action of Liquid Ammonia upon Calomel.

THE decomposition resulting from the action of water of ammonia upon the protochloride of mercury, does not appear to have attracted particular attention, as all writers who speak at all upon the subject, mention ammonia, along with potash and soda, as decomposing calomel into black oxide of mercury. Hennell in particular, states expressly, that calomel decomposed by excess of ammonia, yields a black powder containing in 100 parts, 96 of mercury and four of oxygen. I was therefore rather surprised when experiment showed me that a reaction of a totally different nature takes place, giving rise to a compound possessed of very remarkable properties.

When water of ammonia is poured on calomel, whether sublimed or precipitated, the mass immediately becomes black, and the appearance is not altered by boiling the mixture for a long time. While yet wet the powder remains almost black, but it becomes much lighter on drying, so that when quite dry it is of a dark-gray. This powder is not altered by exposure to air, or to a moderate heat; a portion of it was exposed in a platinum crucible on a sand-bath for several hours to a temperature of $180^{\circ}$ Fahrenheit, without being altered in weight or colour. When moistened it becomes nearly as dark as when first generated, but it again loses its black colour on being dried; boiled with water it does not appear altered in its composition. When this powder is heated in a tube sealed at one end, it first gives a trace of wrter, with much azole and ammonia; then there sublimes calomel mixed with metallic mercury, the decomposition being accompanied with that sort of effervescence which appears in the heating of so many of the substances under examination.

* From the Trans. Roy. Irish Acad., vol. xvii. p. 441 ; being Sections II. and III. of the author's " Researches on the Action of Ammonia upon the Chlorides and Oxides of Mercury;" in continuation from p. 435 of our
last number. 
For the examination of this body, an order of analysis similar to that adopted for white precipitate was pursued.

A. $-148 \cdot 15$ grains of precipitated calomel were boiled for some minutes with a great excess of water of ammonia, and the whole thrown on a filter. The black powder thus obtained weighed 14.1 .92 grains corresponding to 95.79 grains from 100 of calomel.

The liquor that had been filtered off was acidulated by nitric acid and nitrate of silver added in excess; the chloride of silver precipitated was collected and dried: it weighed $44^{\circ} 44$ grains corresponding to $30^{\circ} 0$ from 100 of calomel; and the $30^{\circ} 0$ grains of chloride of silver containing $7 * 401$. But calomel consists in 100 parts of

$$
\begin{array}{ccc}
\text { Mercury . . . . } & 85.117 \\
\text { Chlorine } \ldots . .8 & 14.883
\end{array}
$$

Therefore we have by this experiment, the black powder composed of

$$
\begin{aligned}
& \text { Mercury . . 85.117 and } 88.85 \\
& \text { Chlorine .... } 7 \cdot 482 \quad 7 \cdot 76 \\
& \text { Other matters . . 3.191 } \quad 3.39 \\
& 95 \cdot 790 \quad 100 \cdot 00
\end{aligned}
$$

No. 2. - 153.36 grains of calomel were boiled with water of ammonia for a few minutes, and filtered. The dry dark-gray powder weighed $146 \cdot 71$ grains, corresponding to 95.66 per cent.

The liquor treated with nitrate of silver gave 4.4 .03 of chloride of silver, corresponding to 28.71 of chloride per cent. and which contains $7 \cdot 08$ of chlorine.

Thus we obtain,

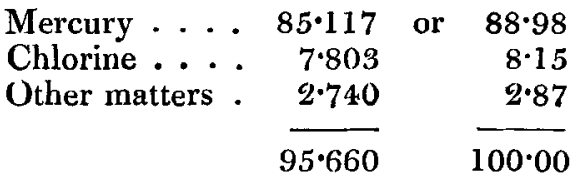

The mean of these experiments gives,

$$
\begin{aligned}
& \text { Mercury . . . 88.91 } \\
& \text { Chlorine ... } 7.95 \\
& \text { Other matters . } \quad 3 \cdot 14 \\
& 100 \cdot 00
\end{aligned}
$$

B.-As the above method necessarily throws the chlorine and mercury estimate rather too high, the following experiment was made, in which the necessary loss produces an opposite effect :

101.37 of the powder were boiled with strong muriatic acid, Third Series. Vol. 11. No.70. Dec. 1837. 3 T 
and an acid solution of protochloride of tin added. The reduction of the quicksilver took place readily, and large wellformed globules appeared; the metal collected and carefully dried, weighed 89.39 grains, or 100 of the powder had given $88 \cdot 18$.

C. -51.42 of the gray powder were dissolved in dilute aqua regia, and a current of sulphuretted hydrogen in excess passed through the liquor. It was found, that owing to free chlorine, the sulphur precipitated invalidated the result. The whole was therefore mixed with nitric acid, and boiled until the sulphuret of mercury was completely decomposed; the liquor was then freed from the particles of pure sulphur and evaporated until all free nitric acid and chlorine were completely dissipated. Being then treated by sulphuretted bydrogen, it yielded a sulphuret, pure and jet black, which collected and dried, weighed 52.39 grains, consisting of

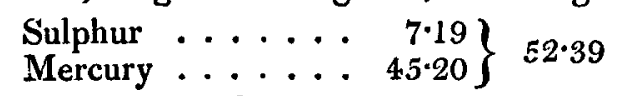

The 51.42 grains therefore contained 45.20 of mercury or 100.00 - $\quad$ - $\quad 87.90$.

In this experiment so much ammonia was lost by the treatment with nitric acid, that its quantity could not be determined.

D.-As in none of these former analyses had the ammonia constituent been determined, the following experiments were made for the purpose of ascertaining its precise quantity:

1st. 66.43 grains were boiled with an excess of solution of iodide of potassium, and the flask being connected with a bent tube dipping into dilute muriatic acid, the heat was kept up until all the ammonia and about half the water had passed over. The liquor was then evaporated to dryness, and yielded a residue of $6.96 \mathrm{grs}$. of sal-ammoniac, consisting of

$$
\left.\begin{array}{lll}
\text { Muriatic acid } \ldots . . & 4 \cdot 73 \\
\text { Ammonia } \ldots . . . & 2 \cdot 33
\end{array}\right\}
$$

or 100 of powder gives 3.36 of ammonia.

The action of potash on the gray powder liberates ammonia likewise; but it was found so difficult to obtain complete decomposition that the method was abandoned. Another process tried, consisted in repeatedly distilling strong muriatic acid off the powder, in order to convert it into metallic mercury, corrosive sublimate, and sal-ammoniac, and thus obtain a quantitative result; but this method also was found of so imperfect action, that it could not be well applied.

Summing up the results of the analyses above recorded, we have for 100 parts of the powder: 


$\begin{array}{cccc}\text { Process. } & \text { Mercury. } & \text { Chlorine. } & \text { Ammonia. } \\ \text { A } & 88 \cdot 91 & 7 \cdot 95 & \\ \text { B } & 88 \cdot 18 & & \\ \text { C } & 87 \cdot 90 & & \\ \text { D } & & & 3 \cdot 36 .\end{array}$

Or the mean result is

$$
\begin{aligned}
& \text { Mercury .......888.33 } \\
& \text { Chlorine ...... 7.95 } \\
& \text { Ammonia . . . . . . 3.36 } \\
& \text { Loss, \&c. . . . . . . 0.36 } \\
& 100 \cdot 00
\end{aligned}
$$

It is evident that we have here a body precisely corresponding to white precipitate; the mercury, however, being in proto-combination. Water of ammonia acting on calomel, abstracts half the chlorine, which is replaced by a corresponding quantity of ammonia in some form of combination. We can accordingly construct two formulæ corresponding to white precipitate; in the first, half the mercury being conserved as protoxidized and combined with an atom of ammonia : in the second, that half of the mercury being directly united to amidogene. The former theory gives from the formula $(\mathrm{Ch}+\mathrm{Hg})$ $+\left(\dot{\mathrm{Hg}}+\mathrm{NH}^{3}\right)$.

$$
\begin{aligned}
& \text { Mercury ...... 87.00 } \\
& \text { Chlorine ...... 7.59 } \\
& \text { Oxygen ........ 1.73 } 100.00 \\
& \text { Ammonia........ 3.68 }
\end{aligned}
$$

and 100 of calomel should yield 97.84 of product; whilst the second, from the formula $(\mathrm{Ch}+\mathrm{Hg})+\left(\mathrm{NH}^{2}+\mathrm{Hg}\right)$ gives,

$$
\begin{aligned}
& \text { Mercury ...... 88.72 } \\
& \text { Chlorine ....... } 7 \cdot 74\} 100.00 \\
& \text { Amidogene....... 3.54 }
\end{aligned}
$$

and 100 of calomel should yield 95.95 of product, which is almost precisely the quantity obtained in experiment.

We here find the evidence in favour of the existence of amidogene in combination to be almost insuperable. I shall nevertheless retain all through this paper the two methods of expression, until by examining the compounds of the other metals, the differences may become so much larger, as to completely prevent their falling within possible limits of error of observation.

Of the Action of Ammonia upon Peroxide of Mercury.

The accurate examination of the action of ammonia upon $3 \mathrm{~T} 2$ 
peroxide of mercury is of very great importance, as the compound resulting, the ammoniuret of mercury, is one of a very remarkable class of bodies, viz. the fulminating compounds containing ammonia; and in addition, the experiments of Guibourt, the only chemist I believe who has made analyses of it, would appear to demonstrate in it, a relation between the number of atoms of ammonia and oxygen, which must influence the ammoniacal theories to a very great extent. These circumstances made me trace out the properties of this body with more exactness than should have been otherwise required.

I have not been able to prepare a substance possessing the external characters of the ammoniuret of mercury described by Fourcroy and Thenard. I have varied in every manner I could imagine, the method of obtaining it; but, although I got a substance constantly the same in its properties and composition, it differed much in appearance from that described by the French chemists. They state, that by digesting liquid ammonia on red oxide of mercury during eight or ten days, the oxide gradually covers itself with a yellowish-white powder which generally passes to a very fine white. I have never obtained it of a pure white, but always with a tinge of yellow, possessing an appearance and affording on analysis, results always the same. The constancy of its properties justifies me, I should think, in considering it as pure, notwithstanding its not exactly agreeing with their result. Unfortunately they did not publish any quantitative analysis of their product; the only one known to me is that in Guibourt's thesis.

In order to prepare ammoniuret of mercury, I precipitated a solution of sublimate by potash, and the precipitate having been well washed from all excess of alkali, was put into a bottle of water of ammonia and left for some days; its colour became much lighter, but never completely white. Other portions of recently precipitated peroxide were boiled in water of ammonia for a few minutes, until the colour ceased to undergo any change: the reaction was very much accelerated by heat. These different portions of product had all the same colour, and were indifferently, but without mixture, used in the following examination without any difference of properties becoming observable.

When this ammoniuret is heated, it gives off much ammonia and azote; a considerable quantity of water collects in the tube, and the matter remaining becomes dark-red, like peroxide; but if it be allowed to cool, it reassumes its whitish colour, and is evidently still unaltered ammoniuret. The reaction evidently does not consist in a separation of the ammo- 
niuret into ammonia and peroxide; but, from the commencement to the termination, there are disengaged water, ammonia, azote, oxygen and metallic mercury. The ammoniuret, like many other mercurial compounds, is dark-red when hot, but of a whitish colour when cold. When a quantity of the ammoniuret is suddenly thrown on ignited coals it explodes very feebly, and far inferiorly to fulminating gold, with which its discoverers have compared it: it dissolves readily in nitric or muriatic acid.

To analyse this compound, processes of a simple nature were sufficient.

A.- 72.07 grains of ammoniuret were dissolved in muriatic acid, and the liquor having been diluted was decomposed by sulphuretted hydrogen. The resulting sulphuret dried and weighed, amounted to $70^{\circ} 08$ grains, consisting of

$$
\left.\begin{array}{l}
\text { Sulphur ............... } 9 \cdot 61 \\
\text { Mercury............60 } \\
\mathbf{6 0} 47
\end{array}\right\}
$$

The liquor and washings evaporated to dryness, gave salammoniac, $9 \cdot 21$ grains, consisting of

$$
\begin{array}{lll}
\text { Muriatic acid .......... } & 6.28 \\
\text { Ammonia } & . . . . . . . . . & 2.93
\end{array}
$$

Hence, supposing the mercury to exist as peroxide, we have as the result of the analysis:

$$
\left.\begin{array}{lr}
\text { Mercury ............... } & 60.47 \\
\text { Oxygen ............... } & 4 \cdot 78 \\
\text { Ammonia ........... } & 2.93 \\
\text { Waier and loss ....... } & 3.89
\end{array}\right\} 72 \cdot 07
$$

or in one hundred parts-

$$
\left.\begin{array}{llr}
\text { Mercury ................ } & 83 \cdot 90 \\
\text { Oxygen ............... } & 6 \cdot 63 \\
\text { Ammonia } & \ldots . . . . . . . & 4 \cdot 07 \\
\text { Water and loss } & \ldots \ldots . . & 5 \cdot 40
\end{array}\right\}
$$

2.- The following analysis was made on a portion of ammoniuret prepared at a different time and in another manner than that used in the former experiment.

67.57 grains were dissolved in muriatic acid and decomposed by a stream of sulphuretted hydrogen. The precipitated sulphuret weighed 65.37 grains, consisting of

$$
\left.\begin{array}{lr}
\text { Sulphur ................ } & 8 \cdot 96 \\
\text { Mercury.............. } & 56 \cdot 4 \cdot 1
\end{array}\right\} 65 \cdot 37
$$

The liquor evaporated to dryness gave 8.15 grains of salammoniac, consisting of

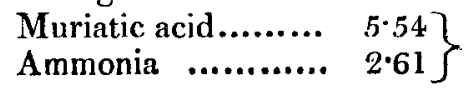


we have therefore the result-

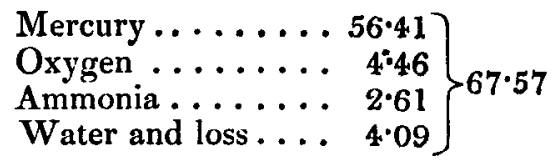

or in 100 parts-

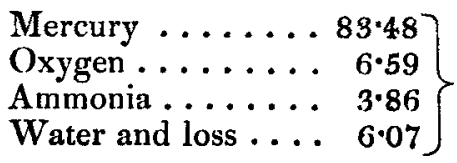

a result almost identical with the former.

B. - 52.22 grains were dissolved in muriatic acid and decomposed by chloride of tin. There were obtained 43.74 of mercury corresponding to 83.76 per cent.

C.-As the constancy of the amount of mercury and ammonia in the preceding results, proved completely that the loss did not arise from error, but probably from water present, the following experiment was made to ascertain whether water existed in such quantity: A small green glass retort was blown, with a pretty long neck; to it was attached a tube containing potash; and the ammoniuret in the retort having been decomposed by a red heat, its gaseous elements were allowed to escape; the mercury condensed in the neck of the retort and the water in the potash-tube; the result, though not absolutely true, is sufficiently accurate for the determination of the point required.

Weight of retort and material ..... 75.38

Weight of retort ......... 63.00

Ammoniuret used $12 \cdot 38$ grains

Weight of retort and mercury-residue. $73 \cdot 35$

Weight of retort .......... 63.00.

Mercury remaining 10.35

Weight of potash-tube before . . . 278.28

Weight of potash-tube after . . . . . 278.95

Water absorbed . . 0.67

We thus obtain as results-

$\begin{array}{lrrrr}\text { Mercury . . } & . & 10.35 & . & 83.62 \\ \text { Water . } & .67 & . & 5.39 \\ \text { Gases and loss . } & 1.36 & . & 10.99\end{array}$

But the gases consist of oxygen and ammonia, the former 
being such as to peroxidize the mercury; and assuming the remainder to be ammonia without loss, we have,

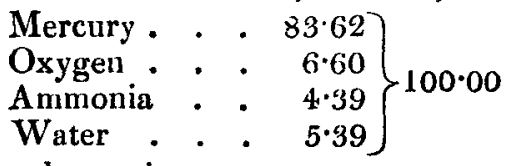

These results summed up, give-

\begin{tabular}{|c|c|c|c|c|}
\hline $\begin{array}{l}\text { Process. } \\
\text { A, No. } 1 .\end{array}$ & $\begin{array}{l}\text { Mercury. } \\
83.90\end{array}$ & $\begin{array}{c}\text { Oxygen. } \\
6.63\end{array}$ & $\begin{array}{c}\text { Ammonia. } \\
4 \cdot 07\end{array}$ & $\begin{array}{l}\text { Water } \\
5 \times 40\end{array}$ \\
\hline - No. 2. & 83.48 & 6.59 & $3 \cdot 86$ & 6.07 \\
\hline & $83 \cdot 76$ & $6 \cdot 60$ & & \\
\hline & $83 \cdot 62$ & $6 \cdot 60$ & $4: 39$ & $5 \cdot 39$ \\
\hline
\end{tabular}

Giving a mean result of

$$
\left.\begin{array}{lr}
\text { Mercury ........ } & 83 \cdot 68 \\
\text { Oxygen ........ } & 660 \\
\text { Ammonia . . . . . } & 4 \cdot 10
\end{array}\right\} 100 \cdot 00
$$

on abstracting the water, we have-

$$
\left.\begin{array}{lr}
\text { Mercury } \ldots \ldots \ldots & 88.67 \\
\text { Oxygen } \ldots \ldots \ldots & 6.99 \\
\text { Ammonia } \ldots \ldots \ldots & 4.34
\end{array}\right\} 100.00
$$

The only analysis of this substance that I am aware of having been published, is that of Guibourt, already quoted, and he considers it to be a compound of oxide of mercury and ammonia in such proportion that the hydrogen of the ammonia could convert the oxygen of the oxide of mercury into water, consequently his formula is the following $\left(3 \ddot{\mathrm{Hg}}+2 \mathrm{NH}^{3}\right)$ and the per centage result:

$$
\begin{aligned}
& \text { Mercury ....... 88.08 } \\
& \text { Oxygen .......6. 6.95 } 100.00 \\
& \text { Ammonia ........ 4.97 }
\end{aligned}
$$

with which my analyses may be considered as completely agreeing. In the abstracts of Guibourt's paper that $I$ have seen, there is not any notice taken of the water present; but yet its constant value shows it to be a chemical ingredient, and we have its atomic proportion, thus-

$$
\frac{2 \mathrm{Hg}}{3 \mathrm{H}}=\frac{405 \cdot 6}{27}=\frac{83 \cdot 68}{5.57} \text { or nearly } \frac{83.68}{5 \cdot 62}
$$

The compound ( $3 \ddot{\mathrm{H}} \mathrm{g}+2 \mathrm{NH}^{3}+4 \dot{\mathrm{H}}$ ) gives us in per cent. composition, the following:

$$
\begin{aligned}
& \text { Mercury ...... 83.72 } \\
& \text { Oxygen ........ 6.60 } \\
& \text { Ammonia ....... 4.72 }\}^{100} \\
& \text { Water . . . . . . . } 4 \cdot 96
\end{aligned}
$$

A result agreeing very closely with that of experiment. 
Admitting that the azotic element is engaged in the combination as amidogene, and not as ammonia, the above formula converts itself into

$$
\left(2 \ddot{\mathrm{H}} \mathrm{g}+\left(2 \mathrm{NH}^{2}+\mathrm{Hg}\right)+6 \dot{\mathrm{H}}\right)
$$

a method of arrangement which we have already met with as an element of the yellow powder, formed by water on white precipitate.

LXXII. On the Nature of Lampic Acid. By Arthur Connell, EsQ., F.R.S.E.*

I $\mathrm{T}$ is well known that Professor Daniell, to whom we are indebted for a knowledge of the properties of this acid liquid, ultimately came to the conclusion that it is acetic acid containing some disoxygenating substance which bestows its property of reducing metallic oxides.

A few years ago I had occasion to examine this acid, as well as that resulting from the action of potash on alcohol, and that obtained by distilling a mixture of alcohol, peroxide of manganese, and sulphuric acid, and I came to the conclusion that they all contained formic acid besides acetic acid. The grounds on which the existence of formic acid in them was inferred, were that they all reduced the oxides and salts of mercury and silver with effervescence, and that they all were capable of yielding perfectly well characterised formates of lead and of magnesiat.

About the same time M. Leopold Gmelin came by independent observation to the same conclusion as myself respecting the acid from alcohol, oxide of manganese and sulphuric acid $\ddagger$; and as the manner in which I had examined the three liquids, the results which I had obtained, and the conclusions which I had drawn regarding them, were the same in all the three cases, I could not avoid regarding M. Gmelin's experiments as amounting to a verification of the view which I had given regarding all the three acid liquids.

In a late memoir, however, on the products of the oxidation of alcohol $\oint$, M. Liebig once more asserted the peculiar nature of lampic acid by maintaining that it was "probable, not to say certain," that lampic acid is identical with a peculiar acid, which this distinguished chemist supposes is formed by the action of oxide of silver on aldehyde, and to which he has given the name of the aldehydic. M. Mitscherlich, in the

* Communicated by the Author.

+ Edinb. New Phil. Journal, vol, xir. p. 231.

$\ddagger$ Poggend. Annal., xxviii. 508.

$\$$ Annales de Chim. et de Physique, lix. 289. 